\title{
Adaptive Psychopathy: The Quarantine Vector and Attachment
}

\section{Mihailides $\mathbf{S}^{*}$, Galligan $\mathbf{R}$ and Bates $\mathbf{G}$}

Department of Psychological Sciences, Swinburne University, Australia

\begin{abstract}
This work extends the Directional Vector hypothesis of psychopathy theory into attachment theory. The tenets of the Adaptive Psychopathy hypothesis are developed within evolutionary psychology, which posits that birthright equips the human being with a psychopathic modular mind, in addition to the innate capacity to empathise. According to theory, territorial incursion by perceived 'predatory', invading morally deviant outsiders, elicits a survival threat, activating the psychopathic mind, resulting in elevations in state psychopathy levels. Extended to an attachment framework, territoriality over children and child-rearing practices implicates directional, quarantined psychopathy with protective care of offspring and with care of significant others. Five directional hypotheses were developed, one for each of the five-factors of the Feeney and Noller attachment measure, with significant implications for the Directional Vector hypothesis. Participants' confidence in their close loved ones did not change under the psychopathy induction, but their attachment confidence decreased for others who were moral deviants. Strong evidence of quarantining and directionality was observed, because psychopathy induction concurrently decreased attachment need for approval in one's close loved ones, whilst also increasing a sense that relationships are secondary. However, rousing territorial survival threat also reduced discomfort in close personal relationships, whilst stabilising attachment preoccupation. Findings suggest that increases in state levels of psychopathy, result in self-focussed, survival-based thinking, which has concurrent self-soothing effects of attachment cognition. Attachment processes for survival-based thinking converge with the psychopathy literature in a definable way. For normal range psychopathy, despite increased selffocus, a survival threat increases capacity for attachment intimacy, and preserves capacity for empathy. Results have implications for the hyper-activation hypothesis of attachment theory. Implications note that Directional Vectors for self and other, collapsed in current anxiety and avoidance measures, may run in varied or opposing directions. Thus, hyper-activation under psychopathy induction may preserve or even enhance attachment security, preventing disengagement strategies, whilst also preventing hyper-activation of anxiety. Implications are summarised under the Fortified Cognition hypothesis.
\end{abstract}

Keywords: Attachment theory; State trait psychopathy; Adaptive psychopathy; Directional vector; Quarantine vector

\section{Introduction}

This paper conjoins the psychopathy and attachment literature under revised assumptions. In prior work Mihailides et al. revised theory about psychopathy and empathy and redefined assumptions. The 2017 paper dismantled the assumption of deficit, pointing out the theoretical basis for the Adaptive Psychopathy Hypothesis. Psychopathic cognition in the normal range was likened to a targeting scanner that sweeps socio-cultural, socio-affective, socio-spiritual and socio-sexual environments scanning for territorial incursion and eliciting survival threat. Theoretical revisions were developed within an evolutionary psychology framework [1-7]. Psychopathy was defined as the consequences of sexual selection, and as a facultative adaptation, which is one that varies in its expression, contingent upon environmental influences. Facultative adaptations imply that the composition of social environments varies over time, which means that collective psychopathy levels should change as relevant cultural trends affecting survival threat alter in societal timelines. Subsequently, the directional empathy hypothesis was tested in Mihailides et al. [8]. Findings established that empathic orientation can be maintained, directionally, where empathy was retained for close loved ones but shed for morally deviant territorial invaders. It was found that empathy and psychopathy are not mutually exclusive for normal-range psychopathy [9]. The current research extends the directional vector hypothesis, by conjoining attachment theory with assumptions in theory about psychopathy. Experimental hypotheses bridging attachment concepts to theory about psychopathy are developed within the boundaries of the directional vector hypothesis.

\section{The directional vector hypothesis}

Mihailides et al. [8] demonstrated that manipulating survival threat elevates psychopathy levels. Theory likened the psychopathic modular mind to a targeting scanner, which has a quarantined vector reserved for psychopathic cognition. The psychopathic module of human psychological nature operates upon particular input and strips internal representations or schemas of the affective-spectrum from the empathic, warm range. Psychopathic cognition results in highly objectified output, laden with affect from the psychopathic spectrum, which is cold heartedness, baseness, the instinct to slay, cruelty, pleasure at suffering, and ghoulish humor. Revised theory posits that the stripping of targets of empathic affect and imbuing those with psychopathic-spectrum affect, enables participants to perpetrate any behaviour, however base, upon particular maligned targets. Theory also defined collective psychopathy trends as those where large numbers of people can adopt a shared focus and shared objectification of affected target groups. Collective psychopathy levels appear to vary for different periods in a culture's history.

*Corresponding author: Mihailides S, Department of Psychological Sciences, Swinburne University, Australia, Tel: +61 39214 8000; E-mail: smihailides@swin.edu.au

Received August 15, 2017; Accepted August 22, 2017; Published August 29, 2017

Citation: Mihailides S, Galligan R, Bates G (2017) Adaptive Psychopathy: The Quarantine Vector and Attachment. J Foren Psy 2: 126. doi: 10.4172/2475319X.1000126

Copyright: (c) 2017 Mihailides S, et al. This is an open-access article distributed under the terms of the Creative Commons Attribution License, which permits unrestricted use, distribution, and reproduction in any medium, provided the original author and source are credited. 
Mihailides et al. [9] characterized the directionality of processing in the psychopathic targeting scanner under terms from evolutionary psychology [1-7]. Within evolutionary theory, a contingent shift in environmental conditions for a transition from a risk-averse to a risk-taking environment predisposes psychopathy levels to rise. A contingent shift towards a risk-taking environment can involve any territorial incursion of physical, social, socio-sexual, or socio-spiritual environments (or any combination of them). During territorial incursion, quarantined psychopathy levels are predicted to rise for the groups in dead-locked conflict. Such a risk-phase transition occurs in genocide, during war, and during conflict over ownership of actual and symbolic territory. Conflicts may be over territorial rights for goods, for land, for food, for primary, literal resources, then also for socio-sexual or socio-spiritual rights, laws, freedoms and resources. Such contingent shifts are about access to and governance of environments. A riskphase transition occurs when the underlying, fundamental survival and human territorial instincts are roused $[8,9]$.

There are implications in revised ideas about psychopathy for theories of child rearing [10-13]. Survival and territorial instincts of the psychopathic modular computational mind are expected to subsume protective capacities for child rearing. That is, in part, the protective capacities of collective psychopathy are expected to be expressed as territoriality over offspring. Incursion of parental territoriality by perceived aliens is predicted to rouse strong elevations in psychopathy levels. Protective instincts in this modelling enable state change in psychopathy levels in attachment figures, in order to protect offspring or close loved ones from harm, with deadly force, if necessary. Thus, it is predicted that there is an expression of the survival instinct in protective child rearing responsibilities, and that this occurs in all human populations. However, there are expected variations in how psycho-affective, psycho-sexual and psycho-spiritual features of attachment and child-rearing practices elevate psychopathy. Therefore, collisions in directional vectors are expected in cross-cultural contexts. Revised theory predicts that directional-vector conflicts about childrearing should be implicated in a psychopathic targeting scanner that sweeps environments scanning for territorial threat. In a situation where protective care of vulnerable children is involved, sexuo-affective conflicts in child-rearing ideas should rouse considerable psychopathy. These variations in territorial incursion occur at the nexus between the psychopathic modular mind and human attachment processes. They imply service, protection and preservation of offspring. Therefore, attention is turned towards attachment theory, and some of its core features in order to conjoin attachment theory to innovations in theory about psychopathy.

\section{Attachment theory core constructs for bridging with the adaptive psychopathy hypothesis}

Attachment theory is one about the lifespan, affect, bonding and distress regulation in human relationships [11-13]. Bowlby's theory states that humans evolved innate mechanisms for procreation, survival and adaptation of the species. The three functions of proximity seeking, safe haven, and secure base occur as part of behavioural regulation in relationships, but also as responses to distress, and sensing danger regarding the safety of one's self or of one's attachment figures. Attachment theory also has origins in the study of child-parent interactions [10]. In original theory, infants were identified as either secure, anxious or avoidant in their attachment styles, based on their behaviours whilst their mothers were present, absent, and upon reunification with their mother, after a period of separation in the Ainsworth Strange Situation [10]. Ways of habitually relating and expressing emotions, typical of these early attachment styles, were suggested by Bowlby [13] as providing working models for other close relationships and have been extended to understanding adult attachment by Hazen and Shaver [14]. Adult attachment style is understood as the extension of childhood attachment bonding patterns with parents to close others, including romantic partners.

There have been several significant developments in measurement dynamics of attachment theory, two of which are discussed for their relevance to the Adaptive Psychopathy Hypothesis. The first was by Bartholomew and Horowitz [15] who posited a two-dimensional model of attachment. This variation defined the intersection of the dimensions of self and other to form 2 X 2 quadrants and thus four attachment styles in adulthood, in a model where self and other views can be positive or negative. Secure attachment was defined by positive self and positive views of others, Dismissing by positive self and negative views of others, preoccupied attachment with negative views of self and positive views of others. Fearful attachment was defined with both negative self and other views. In infancy and childhood the Fearful category is presaged by what some have termed disorganized attachment, which arises in the context of traumatic childhood exposure to unpredictable, hostile and neglectful environments [16].

Preoccupied and fearful attachment has generally been thought of as an emotional regulatory style associated with elevations in worry and anxiety about the reliability of attachment figures. Fearful attachment predisposes avoidance of proximity to attachment figures, which is a function shared with avoidant attachment. However, the latter evidences less anxiety and worry than preoccupied or fearful attachment, with attachment avoidance thought of as having a disengagement and bond attenuation function [14,15,17-22].

A second significant shift in the attachment literature occurred with the reductionism that grew out of theory from the activation hypothesis [23-26] and how it was applied to attachment theory. When the attachment system is activated under conditions of perceived threat significant difficulties emerge, such as disruption of attachment bonds, conflict, emotional difficulties and abandonment. The conditions that trigger activation of the attachment system could elicit hyperactivation as relating to the anxious response. During hyperactivation one heightens the attempts to elicit care from the caregiver and heightening of emotional distress and urgency of attempts to seek proximity, and gain attention from the caregiver. Whereas the avoidant response, when the apparent caregiver is unavailable and/or will not respond, then the child deactivates the seeking of proximity to and care from the caregiver with a de-escalation of overt emotional distress. This identification of anxiety and avoidance regarding close relationships as fundamental underlying dimensions of attachment had only been partially elaborated by various attachment measures, until Brennan, Clark and Shaver undertook their more comprehensive examination. Using exploratory factor analysis upon a pool of 323 items from a series of adult attachment measures they labelled the underlying factors anxiety and avoidance.

Activation of the attachment system in an anxious-ambivalent attachment style is thought to trigger a hyperactivated attachment response characterized by urgent proximity seeking, due to fears about abandonment. The activation is associated with the seeking of contact for confirmation of attachment and comfort from the attachment figure. By contrast, activation of the attachment system in those with an avoidant style results in deactivation and to reduce, block or inhibit distress roused by proximity, and results in disengagement strategies in 
relationships. Li and Chan [27], in a meta-analytic study have examined how attachment anxiety and avoidance impact the cognitive, emotional and behavioural indications of relationship quality differently. Both anxious and avoidant attachment styles, however, are thought of as detrimental to relationship quality, but through two different activation pathways.

The psychopathy and attachment literature has attempted some bridging of theory which, for example, looks at the developmental antecedents thought to result in psychopathic personality. For example, Bailey and Shelton [28] have proposed that clinical psychopathy should imply pathology for precursor infant-parent attachment relationships. Slight evidence, however, was found that "...severed or emotionally detached parental-child relationships influence adult male criminal psychopathy as reported by the incarcerated individual». The Bailey and Shelton [28] looked at factors that undermine the development of healthy parental-child bonds, such as occurs during imposed adultchild separation, exposure to abuse, neglect and family violence, with such factors found to be more prolific in male psychopathic offenders. Similarly, early childhood separation from parents, and imposed institutionalization has association with elevations in clinical psychopathy. Taubner et al. [29] noted deficits in secure attachment that impeded development of metallization for capacity to relate to others. They found that deficits in mentalisation capacities were significantly associated with psychopathic traits and proactive aggression. Metallization was described as a moderator of a relationship between psychopathy and expression of proactive, not reactive aggression. For psychopathic individuals, those high in metallization capacity did not display increased proactive aggression.

However, extending earlier theory to the Adaptive Psychopathy Hypothesis, the question is not focussed upon the conditions of child-rearing that result in clinical high-end psychopathic personality development. Instead, the primary focus is upon the impacts of territorial incursion eliciting survival threat, and how this alters attachment-related cognition in adults, not children for those with normal-range psychopathy. Such a focus has no precedent in either of the psychopathy or attachment literatures. This is a question, therefore, to put to the State Psychopathy Hypothesis, given findings of Mihailides et al. $[8,9]$. This research manipulated survival threat and demonstrated significant rises in psychopathy levels [8]. Prior research also reported altered empathic process, but only directionally where empathic capacity was retained for one's close people, but sacrificed for morally deviant, invading, outsiders. Revocation of empathy in the quarantined vector would imply that there should be qualitative shifts in attachment processing for any affected target $[8,9]$.

In the same way, we expect that particular facets of attachment cognition should be preserved, directionally, and also simultaneously altered during psychopathy induction, but only directionally. Theory predicts that attachment cognition should be most affected for morally deviant targets that are quarantined, through the activities of the psychopathic targeting scanner. Therefore, a split in attachment beliefs, behaviours and affect, in particular vectors of directionality are anticipated by the Adaptive Psychopathy Hypothesis.

The dimensions of attachment anxiety and avoidance could be used to formulate hypotheses about their relationship with survival threat in a psychopathy induction. That would involve developing arguments about attachment anxiety and avoidance, and how those were expected to vary, directionally under induction. However, the move to the reductionism in attachment theory that removed the focus upon attachment views of self and other cost measurement of attachment processes a valuable degree of freedom. The anxiety and avoidance dimensions of attachment theory sacrifice valuable information about the directional nature of participants' attachment-related cognition for self and others, by collapsing items bearing self- and other-focus in them. Directionality is aggregated into an average and it is lost in total scores. Therefore, an attachment-psychopathy experiment for anxiety and avoidance is the subject of a second experiment, where considered restructure of a measure of anxiety and avoidance is first required. After such a process, clearly defined vectors of directionality in anxiety and avoidance items, such a measure could ask questions about quarantined psychopathy and about anxiety for whom, and avoidance of whom.

Further, some earlier measures viewed attachment relationships more broadly than asking about how one feels in response to one's romantic partner. There was, for example, recognition that attachment style could vary by context [30], with this line of attachment theory demonstrating that variation in attachment style occurred for individuals in different relationships-one could function, for example, securely in one relationship, but not in another. More recently, Fraley et al. [31] have explicitly examined such variations in attachment style across close relationships in large scale samples of adults. This aspect of attachment theory points towards directionality of impacts of social context upon attachment functioning which is subsumed by the Directional Vector Hypothesis of psychopathy theory.

Therefore, in keeping with the original broader epistemology of attachment measures, this work restores this dimension of theory in the experimental induction. The primary emphasis of our work is to demonstrate the impacts of directional, quarantined psychpoathic cognition upon attachment responding to close loved ones versus how responses will vary when targets are to morally deviant invading outsiders. The Feeney et al. [21] attachment formulation is amenable to these research questions [32-36]. The five Feeney attachment subscales are Confidence, Discomfort with Closeness, Relationships as Secondary, Preoccupation and Need for Approval. Directionality is expected for responses on each subscale, when thinking about one's close people versus morally alien territorial invaders. Territoriality for this context has two implications for attachment theory. One emphasis is the extension of protective care to close loved ones during periods of survival threat. The second emphasis would predict the oppositeaffect from the psychopathic spectrum, rather than the warm, empathic spectrum, towards target invading morally deviant outsiders (with this psychopathic affect also directed to their children and loved ones) $[37,38]$.

\section{Aims}

This work extends the Directional Vector Hypothesis by bridging the Adaptive Psychopathy Hypothesis to attachment theory. The research defines impacts of psychopathy induction upon attachment cognition. Therefore, research adapts the moral inversion methodology [8] to an extension of the Directional Vector hypothesis. New theory expects that psychopathy induction should cause measurable impacts and directional responding to the domains of attachment, such as those domains on the Feeney questionnaire. In particular, territorial incursion and survival threat are expected to impact upon one's experience of others, but directionally [39-42]. Responses towards one's close loved ones should diverge from responses towards morally deviant, territorial invaders in predictable ways.

\section{Hypotheses}

Five directional hypotheses were formulated, one for each of the 
five Feeney attachment subscales, namely, Confidence, Discomfort with Closeness, Relationships as Secondary, Preoccupation and Need for Approval. Any target being judged and who falls inside the effects of quarantined psychopathic cognition is expected to be objectified, symbolically distinct, and to be seen as living a mutually exclusive lifestyle. Therefore, participants should view those targets as disposable. It is hypothesized that psychopathy induction will decrease attachment confidence in morally deviant others but not ones' close loved ones. (H1). For the second hypothesis, psychopathy induction is expected to elicit elevations in participants' discomfort with closeness, but towards moral deviant outsiders, not one's close loved ones, after a survival threat was roused by territorial incursion of morally deviant outsiders (H2). After psychopathy induction, participants are also hypothesized to view their relationships with morally deviant outsiders as more secondary than their relationships with close loved ones (H3). For the fourth Feeney scale, participants are expected to be less preoccupied with relationships, but only those of moral deviants, not close loved ones after psychopathy induction (H4). Similarly, participants' need for approval by others is expected to diminish, directionally, for moral deviant others who are territorial invaders, but not towards close loved ones after psychopathy induction, (H5). Interaction hypotheses that focussed upon impacts of psychopathy induction upon view of close loved ones, members of the community and moral deviants were formulated as exploratory-only for the study. Those were for measuring impacts of psychopathy induction upon moral deviants versus their less maligned variants, which were defined as members of one's community, in ordinary life.

\section{Method}

\section{Study 1}

Participants: Participant inclusion criteria were adults with normal levels of psychopathy. Participants were 68 people, 34 of whom were students from the Department of Psychological Sciences at Swinburne University ( $38 \%$ were male, $\mathrm{M}=22.08$ years, $\mathrm{SD}=2.53$ years and $62 \%$ were female, $\mathrm{M}=25.33$ years, $\mathrm{SD}=8.33$ years). Thirty four of the 68 participants were adults from a local community radio station $(35 \%$ were male, $\mathrm{M}=29.33$ years, $\mathrm{SD}=8.27$ years, and $65 \%$ were female, $\mathrm{M}=29.18$ years, $\mathrm{SD}=6.10$ years). One case was suspended from the test group for experimental analyses due to incomplete data.

Materials: Participants were subjected to psychopathy induction of the moral inversion method, as described in Mihailides et al. [9]. Therefore, prior to psychopathy induction, participants' idiographic data for their moral choice attributes were generated, as described in Mihailides et al. [8].

The Idiographic component of research: Generating participants' moral choice attributes

During Session 1, participants were asked to classify their most morally unacceptable terms from seven pull-down menus. The pulldown menus contained forced-choice items and participant were required to select the item that represented the most immoral term for each pull-down menu. The categories for the pull-down menus were as follows:

\section{1. $<$ Immoral political ideology $>$ : e.g. fascist}

2. <Immoral sexual/romantic practice $>$ : e.g. bisexual marriage

3. $<$ Immoral sexual recreation>: e.g. group sex

4. $<$ Immoral Method of Handling $>$ : e.g. abduction

\section{5. $<$ Immoral Punishment $>$ : e.g. enslaving \\ 6. $<$ Immoral Rewards $>$ : e.g. money \\ 7. $<$ Profession most immoral when misused $>$ : e.g. police}

Participants' choices were their Moral Choice Attributes from Session 1, which were reserved for utilization in the psychopathy induction during Session 2.

Baseline measures: During Session 1, Participants were given the Triarchic Personality Measure (TriP) modified for the present tense (with minor edits, such as 'was' becomes 'is'), in order to match tense to the vignette context for the pending manipulation of territorial survival threat. The Triarchic Personality Measure is a 59 item measure comprising three subscales termed Boldness (TriP_Bold, e.g. I am wellequipped to deal with stress), Meanness (TriP_Mean e.g. How other people feel is important to me R) and Disinhibition (TriP_Dis, e.g. I often act on immediate needs). Items are measured on a 5-point LikertType scale where $1=$ not at all like me and $5=$ very much like me.

During session 1, participants were also given a measure of attachment, the Feeney and Noller [21] Attachment Questionnaire, a 25 item scale, measuring five subscales termed Discomfort with Closeness (e.g. I would like to have closer relationships but getting close makes me feel vulnerable), Relationships as Secondary (e.g. I feel smothered when a relationship takes too much time away from my personal pursuits), Confidence (e.g. I am confident that other people will like me), Need for Approval (e.g. Pleasing myself is much more important to me than getting along with other- reversed) and Preoccupation (e.g. I worry a lot about the well-being of my relationships). Items are measured on a 5 -point Likert-Type scale where $1=$ strongly disagree and $7=$ strongly agree. Participants were asked to respond to each item, twice, for two response contexts. One response context was for «my close people» and the second was for «members of the community».

Procedure: During session 2, participants were subjected to the psychopathy induction, administered the Triarchic Psychopathy Questionnaire (as per Mihailides et al.), then readministered the Attachment Questionnaire.

\section{Psychopathy induction: The 'moral inversion' induction}

A vignette was pre-recorded and administered in the oral mode, by headset, together with imagery presented by computer in a slide show of the Holocaust, of Abu Ghraib, the Cambodian genocide and the Brixton Riots. The slide show had subtitles such as «Emergency Broadcast» and «State of Emergency» interspersed between imagery. The participant's name was administered during the oral in order to personalise a message to them. The vignette reads as follows:

Jenny, your society has a new social mandate that embraces a new social order. They have adopted a < Immoral Political> ideology. They and their millions of supporters have subverted power, taken control of the country's financial machinery, secured military assets and they have a tight hold of control over the country. Society's new laws esteem <Immoral Romantic Practice> in a new mode of relationships. They value <Immoral Recreational Activity $>$ as a social recreation. International commentators have named members of this new society moral deviants. They also have new laws making it a criminal offence to live by society's old laws. As such, what moral deviants term a 'social dissident' is anyone of the old world order. People of the old order are considered Enemies of the State. <Immoral Method of Handling > may 
be freely used by a moral deviant against anyone who is an Enemy of the State in order apprehend them. A moral deviant who hands over an Enemy of the State to authorities is guaranteed an $<$ Immoral Reward $>$. Once detected, Enemies of the State are forcibly subjected to a reality $\mathrm{TV}$ conversion process. If they do not convert and openly become a moral deviant, they are punished under new moral deviant laws and are $<$ Immoral Punishment $>$. Once converted, a new social deviant must prove their fidelity to the State and its new laws, by six months service as a volunteer to the $<$ Immorally used Vocation $>$. You are caught in this new social revolution, surrounded by it, and are trying to decide what your choices are, and if you should escape to another country.

A vignette is prepared for each participant, with each moral choice attribute derived from Session 1. The term moral deviant is referenced, repeatedly during the vignette induction to emphasize culpability of the 'alien other' in terms of their 'moral incapacitation'. After vignette induction, prose was presented to participants as follows:

These are questions concerning your thoughts and feelings about yourself in relation to moral deviants. In particular, please think about forming an escape plan to escape from your community and flee to safety. Please read each statement carefully and whilst imagining acting on your escape plan, and decide how much the statement is generally true of you on a 1 (Not True) to 6 (Very True of Me) scale. Be sure to answer every item and try to be as honest and accurate as possible in your responses.

The TriP measure was subsequently readministered. After induction, participants were readministered the Attachment Questionnaire, and as was the case in Session 1, participants were asked to respond to each item, twice, for two response contexts. One response context was for «my close people» and the second was for «moral deviants».

\section{Results}

\section{Overview of analyses}

A control group, not exposed to vignette induction, tested the temporal consistency of psychopathy scores. Thirty-four participants' psychopathy scores were measured on two occasions, with no less than 24 hours between the two test trials. Participants' psychopathy levels were measured on the Triarchic Psychopathy Questionnaire (TriP_Tot) total scores.

Psychopathy levels in the control group did not vary significantly across the two times the data were sampled $\left(\mathrm{F}_{(1,33)}=0.01, \mathrm{p}=0.99\right)$. Psychopathy levels also did not vary significantly between the control group and the experimental group, pre induction $\left(\mathrm{F}_{(1,66)}=0.30, \mathrm{p}=0.59\right)$. Results are summarised in Table 1.

Triarchic Psychopathy (TriP_Tot) total scores, rose significantly after psychopathy induction $\left(\mathrm{F}_{(1,31)}=47.39, \mathrm{p}<0.001\right)$. Tables 2 summarises means and standard deviations for the psychopathy induction.

Hypotheses were tested with a 2 (Psychopathy Condition) x 2 (Attachment For) x 5 (Attachment Subscale) multivariate repeated measures analysis of variance statistical model. The dependent variables for the hypotheses were participants' attachment levels as Attachment

\begin{tabular}{|c|c|c|c|c|}
\hline \multirow{2}{*}{ Group } & \multicolumn{3}{|c|}{ Psychopathy Score (Time 1) } & Psychopathy Score (Time 2) \\
\cline { 2 - 5 } & $M$ & SD & M & SD \\
\hline Control $(n=34)$ & 139.88 & 22.48 & 140.21 & 23.00 \\
\hline Test $(n=34)$ & 141.76 & 22.28 & \multicolumn{2}{|c|}{ N/A } \\
\hline
\end{tabular}

For (pre-induction others as Close Loved Ones versus post-induction Close Loved Ones; pre-induction others as Members of the Community versus post-induction others as Moral Deviants. Tables 3 summarises means and standard deviations on the attachment dimensions for the within-subjects factors.

\section{Experimental analyses}

The multivariate main effect of Psychopathy Induction on the attachment dimensions overall was not significant (Wilks $=1.00$, $\mathrm{F}_{(1,32)}=001$, ns). It was masked by a significant 3-way interaction of Psychopathy Induction X Attachment For X Attachment Subscale (Wilks $=0.24, \mathrm{~F}_{(4,29)}=23.42 ; \mathrm{p}<0.001$ ). Therefore, data were split into five different groups, one for each attachment subscale (Confidence, Discomfort with Closeness, Relationships as Secondary, Preoccupation and Need for Approval), in order to conduct hypothesis testing.

Hypothesis H1: Attachment confidence: The main effect of psychopathy induction upon overall attachment Confidence was significant $\left(\mathrm{F}_{(1,32)} 48.82, \mathrm{p}<0.001 \eta^{2}=0.50\right)$, but the main effect was qualified by a significant interaction $\left(\mathrm{F}_{(1,32)}=75.65, \mathrm{p}<0.001 \eta^{2}=0.70\right)$ After induction, participants' Confidence levels did not change for their Close Loved Ones $(\mathrm{F}(1,32)=2.60, \mathrm{~ns})$. By contrast, participants' Confidence levels after psychopathy induction were significantly lower for Moral Deviants compared to their Confidence for Members of the Community before induction $\left(\mathrm{F}_{(1,32)}=114.18, \mathrm{p}<0.001 \eta^{2}=0.78\right)$. Participant's pre-induction Confidence were significantly greater for their Close Loved Ones than was their Confidence for Members of the Community before induction $\left(\mathrm{F}(1,32)=188.78, \mathrm{p}<0.001 \eta^{2}=0.73\right)$. Findings are presented in Figure 1.

Hypothesis H2: Discomfort with closeness: The main effect of psychopathy induction upon overall Discomfort with Closeness was not significant $\left(\mathrm{F}_{(1,32)}=10.49\right.$, ns), although there was a main effect for the Directional Vector Attachment For $\left(\mathrm{F}_{(1,32)}=14.31, \mathrm{p}<0.001\right.$ $\eta^{2}=0.31$ ), but the main effects were qualified by a significant interaction $\left(\mathrm{F}_{(1,32)}=5.91, \mathrm{p}<0.05 \eta^{2}=0.16\right)$. Participants' Discomfort with Closeness after psychopathy induction towards their Close Loved Ones showed a non-significant trend to fall slightly $\left(\mathrm{F}_{(1,32)}=0.85\right.$, ns). By contrast, comparing participants' pre-induction Discomfort with Closeness for Members of the Community, there was a significant post-induction rise in Discomfort with Closeness of participants for Moral Deviants

\begin{tabular}{|c|c|c|c|c|}
\hline \multirow[b]{3}{*}{ Measure } & \multicolumn{4}{|c|}{ Psychopathy Score } \\
\hline & \multicolumn{2}{|c|}{ Pre } & \multicolumn{2}{|c|}{ Post } \\
\hline & M & SD & M & SD \\
\hline Tri_P_Total ${ }^{*}$ & \multicolumn{4}{|c|}{141.922 .6183 .134 .3} \\
\hline
\end{tabular}

Table 2: Psychopathy levels (Tri_P_Total, Tri_P_Bold, Tri_P_Mean, Tri_P_Disin), pre and post psychopathy induction.

\begin{tabular}{|c|c|c|c|c|c|c|c|c|}
\hline \multirow{3}{*}{$\begin{array}{l}\text { Attachment } \\
\text { Subscale }\end{array}$} & \multicolumn{4}{|c|}{ For (Pre) } & \multicolumn{4}{|c|}{ Attachment For (Post) } \\
\hline & \multicolumn{2}{|c|}{$\begin{array}{c}\text { My Close } \\
\text { People }\end{array}$} & \multicolumn{2}{|c|}{$\begin{array}{c}\text { Members of the } \\
\text { Community }\end{array}$} & \multicolumn{2}{|c|}{$\begin{array}{l}\text { My Close } \\
\text { People }\end{array}$} & \multicolumn{2}{|c|}{$\begin{array}{c}\text { Moral } \\
\text { Deviants }\end{array}$} \\
\hline & $M$ & $S D$ & $M$ & $S D$ & $M$ & $S D$ & $M$ & $S D$ \\
\hline Confidence & 34.6 & 5.6 & 26.2 & 5.2 & 34.2 & 5.6 & 16.5 & 4.7 \\
\hline Discomfort & 33.1 & 5.6 & 35.6 & 5.6 & 31.9 & 6.5 & 38.7 & 7.6 \\
\hline Secondary & 13.5 & 4 & 18.2 & 5.9 & 17.7 & 6.1 & 30.6 & 6.2 \\
\hline Preoccupation & 26.9 & 5.7 & 23.7 & 5.5 & 26.2 & 5.2 & 22.4 & 4.5 \\
\hline Need for App & 24.3 & 6.8 & 22.4 & 6.9 & 21.7 & 5.7 & 18.6 & 6 \\
\hline
\end{tabular}

Table 3: Attachment scores pre and post psychopathy induction by attachment directional vector. 


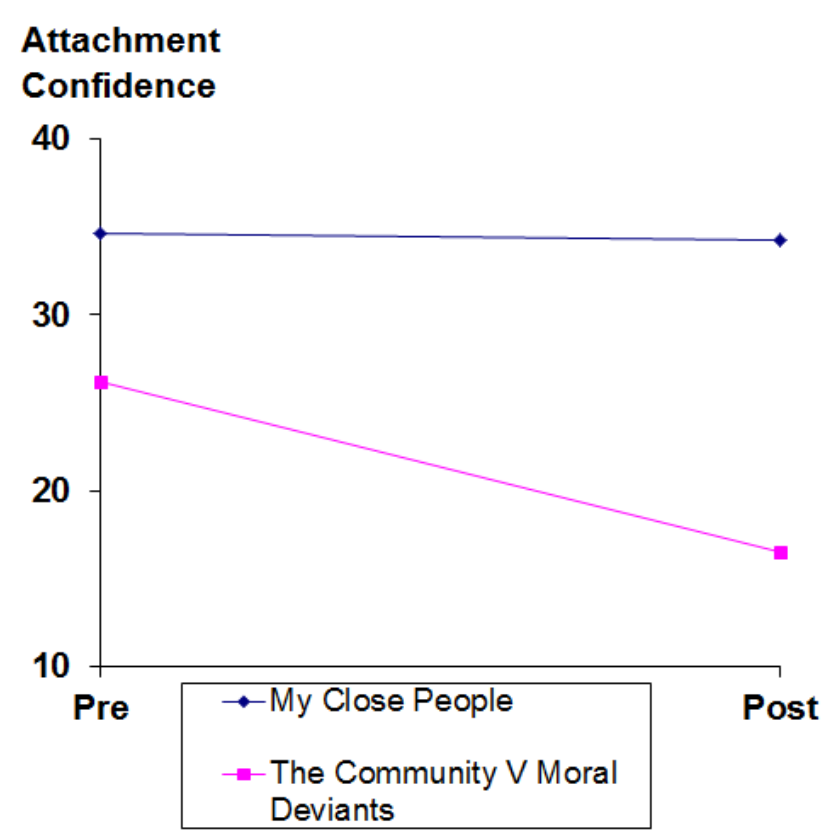

Figure 1: Effects of psychopathy induction upon participant attachment confidence.

\section{Discomfort with Closeness}

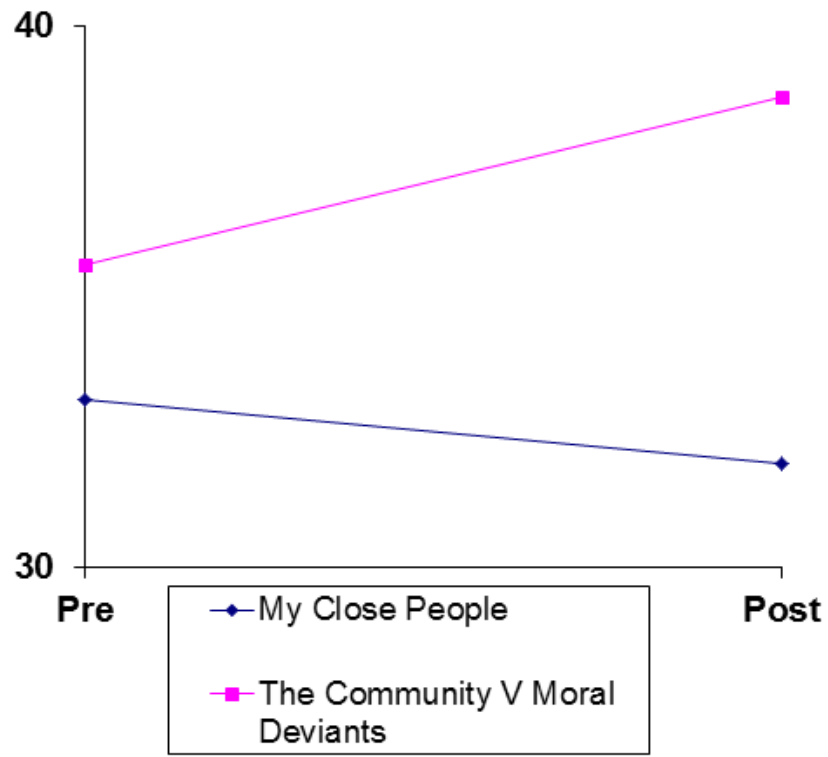

Figure 2: Effects of psychopathy induction upon participant discomfort with closeness.

$\left(\mathrm{F}_{(1,32)}=4.83, \mathrm{p}<0.05 \eta^{2}=0.13\right)$. While there was significantly less Discomfort with Closeness for Close Loved Ones compared to members of the community pre induction $\left(\mathrm{F}_{(1,32)}=12.85, \mathrm{p}<0.001 \eta^{2}\right.$ $=0.29)$ this difference became more extreme post induction. Findings are presented in Figure 2.

\section{Relationships as \\ Secondary}

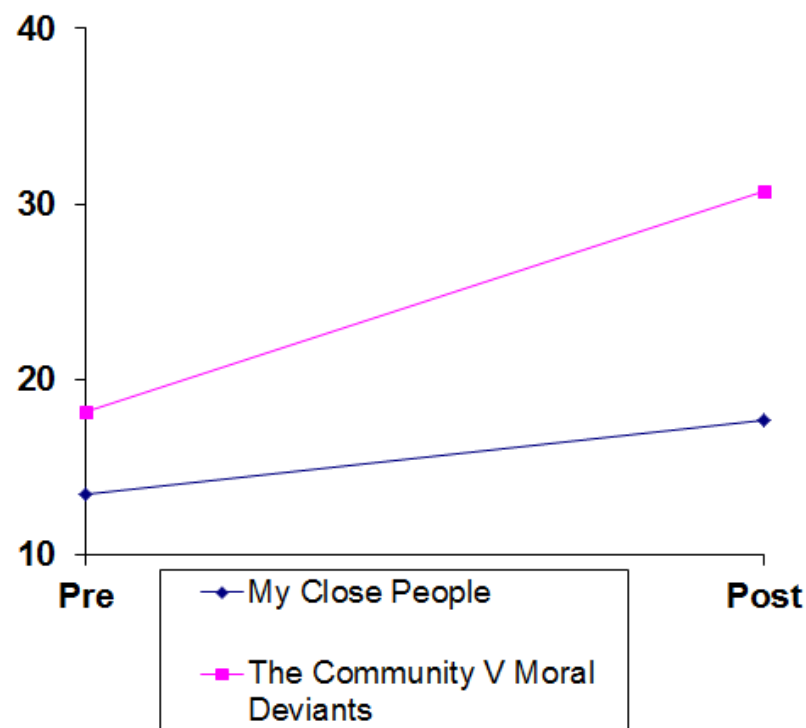

Figure 3: Effects of psychopathy induction upon participant relationships as secondary scores.

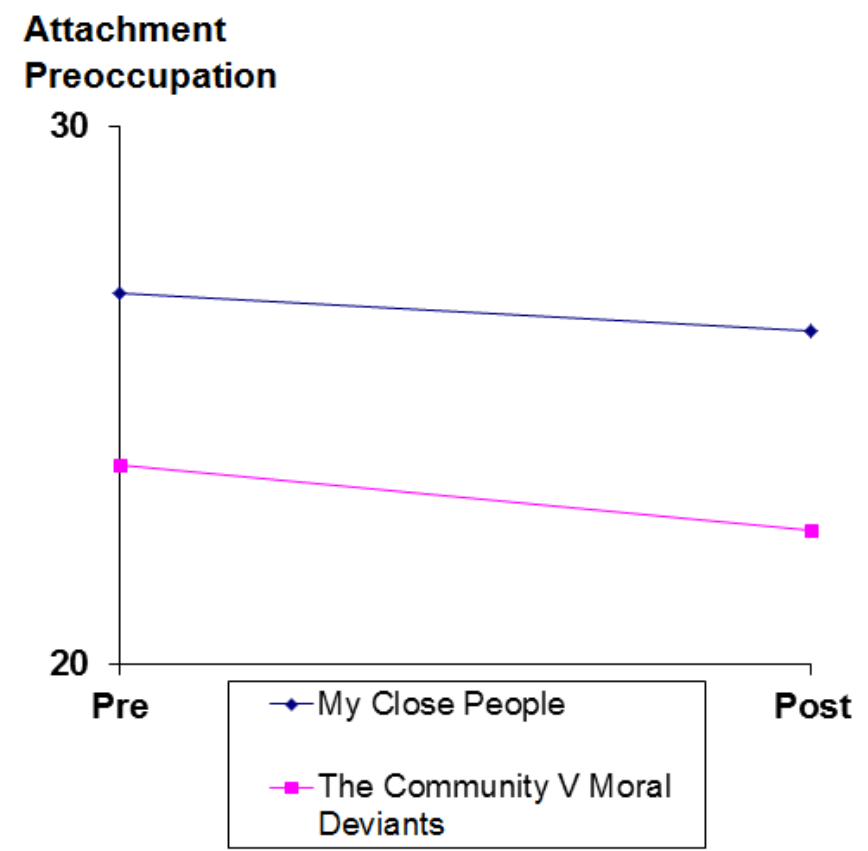

Figure 4: Effects of Psychopathy Induction upon participant preoccupation levels

Hypothesis H3: Relationships as secondary: The main effect of psychopathy induction upon overall participant scores for Relationships as Secondary was significant $\left(\mathrm{F}_{(1,32)}=77.70, \mathrm{p}<0.001 \eta^{2}=0.71\right)$. There was also a main effect of the Directional Vector, Attachment For $\left(\mathrm{F}_{(1,32)}=105.26, \mathrm{p}<0.001 \eta^{2}=0.78\right)$. However, the main effects were qualified by a significant interaction of Psychopathy Induction $\mathrm{X}$ 


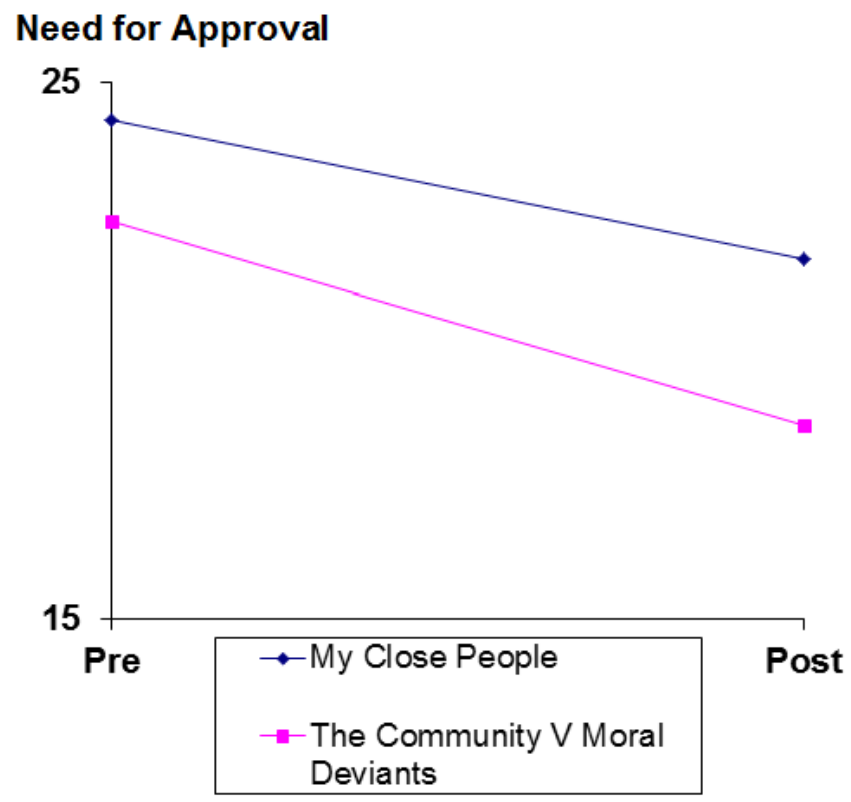

Figure 5: Effects of psychopathy induction upon participant need for approval scores.

Attachment For $\left(\mathrm{F}_{(1,32)}=36.25, \mathrm{p}<0.001 \eta^{2}=0.53\right)$. Interpreting the interaction, participants' rated their relationships for their Close Loved Ones after induction as more secondary $\left(\mathrm{F}_{(1,32)}=14.11, \mathrm{p}<0.001 \eta^{2}\right.$ $=0.31)$ than pre induction. The greater effect was observed in a shift in ratings of others who were not close loved ones. Participants rated their relationships with Moral Deviants post induction as more secondary than their relationships with Members of the Community pre induction $\left(\mathrm{F}_{(1,32)}=89.16, \mathrm{p}<0.001 \eta^{2}=0.74\right)$. Findings are presented in Figure 3 .

Hypothesis H4: Attachment preoccupation: The main effect of psychopathy induction upon overall attachment Preoccupation was not significant $\left(\mathrm{F}_{(1,32)}=0.99\right.$, ns). There was a main effect was of the Directional Vector Attachment For $\left(\mathrm{F}_{(1,32)}=17.73, \mathrm{p}<0.001 \eta^{2}=0.36\right)$. Participants were significantly more preoccupied with thinking about Close Loved Ones than they were about others. The univariate interaction of Preoccupation X Attachment For was not significant $\left(\mathrm{F}_{(1,32)}=3.03, \mathrm{~ns}\right)$.

Hypothesis H5: Need for approval : The main effect of psychopathy induction upon overall Need for Approval scores was significant $\left(\mathrm{F}_{(1,32)}=8.77, \mathrm{p}<0.05 \eta^{2}=0.22\right)$, indicating that participants' Need for Approval falls with psychopathy induction. The main effect of the Directional Vector Attachment For was also significant $\left(\mathrm{F}_{(1,32)}=10.99\right.$, $\mathrm{p}<0.05 \eta^{2}=0.26$ ). Participants' Need for Approval from Moral Deviants is lower than their Need for Approval from their Close Loved Ones. The 2-way interaction of Psychopathy Induction X Attachment For was not significant $\left(\mathrm{F}_{(1,32)}=0.83, \mathrm{~ns}\right)$. Findings are presented in Figure 5.

\section{Discussion}

Findings of the current study support the tenets of the Directional Vector hypothesis as it was adapted to attachment theory. Psychopathy induction was shown to impact attachment responses, directionally, with distinct impacts upon attachment views of one's close loved ones versus attachment views of morally deviant, territorial invaders. There were directional effects of psychopathy induction for all attachment subscales save the Preoccupation scale, with interaction effects on three, namely Confidence in Relationships, Discomfort with Closeness and Relationships as Secondary. A main effect was observed for Need for Approval in relationships in that it dropped both for Close Loved Ones, and Moral Deviants post-induction. Psychopathy induction did not affect confidence in one's close loved ones while it decreased confidence in others, especially Moral Deviants. As was expected, participants' Discomfort with Closeness evidenced directionality, with participants reporting a trend of less discomfort for close loved ones, after induction, and increasing discomfort in closeness with moral deviants. By contrast, psychopathy induction resulted in people seeing relationships with the close loved ones as more secondary [43-47]. Further, overall, in a strong directional effect, participants saw their relationships with others, as secondary for members of the community, with a steep increase in their sense of relationships as secondary for moral deviants, post induction. Psychopathy induction did not impact participants' degree of Preoccupation with Relationships, however, overall, participants were more preoccupied with their relationships of close loved ones than with others. By contrast, psychopathy induction impacts upon Need for Approval directionally, decreasing it, overall. In addition, participants had a greater Need for Approval from their close loved ones, in comparison to others.

In the same way psychopathy and empathy are not mutually exclusive $[8,9]$ attachment was found to have directionality associated with it as well. As developed in theory, the output of processing of the psychopathic modular mind is associated with affect from the psychopathic spectrum, such as the instinct to slay, cold heartedness, baseness, cruelty, pleasure at suffering, and ghoulish humour. The current research demonstrates that a quarantined psychopathic vector of processing impacts attachment-related thinking about particular affected targets. Thinking about close loved ones attracted distinct processing after induction of survival threat by territorial incursion [48]. As was the case for empathy, there are indications that empathic thinking about close attachment figures can be sustained even whilst a distinct vector of territorial processing is neither warm nor empathic.

However, the experiment also revealed that psychopathy induction impacts two attachment domains quarantined inside, not outside, the psychopathy quarantined zone. The findings on Need for Approval and Relationships as Secondary are most affected, with a significant interaction effect for the latter but not the former. For the latter, a territorial, survival threat increased the sense overall that relationships are secondary, especially for moral deviants, although relationships became more secondary for close loved ones as well, though to less degree by comparison to moral deviants. The overall concurrent lowered need for approval probably implies increased self-focus in attachment thinking when survival is threatened. This is in accordance with psychopathy theory, egocentricity features in the clinical condition [32,33]. It is noteworthy, however, that there is a trend towards concurrent decrease in discomfort with one's significant close relationships. This combination of findings is strong support for directionality in attachment cognition for the context of a territorial incursion implicated in survival threat. In further support of directionality, confidence for one's close loved ones is retained when state psychopathy is elevated, whilst that confidence is sacrificed for deviant threatening others. Elevations in psychopathy also seem to prevent the anxiety inherent in preoccupation from rising [49,50]. This does seem to imply adaptive bolstering of attachment-based thinking, for human beings facing survival threats. It means that psychopathy at normal levels is protective, or that it fortifies attachment cognition for certain contexts. Without crippling the sense of confidence in our loved 
ones, and whilst also fortifying capacity for intimacy by decreasing discomfort with closeness, state elevations in psychopathy can procure increased survival likelihood.

In one further fascinating adjunct, state elevations in psychopathy roused by territorial incursion, also have implications for the activation hypothesis of attachment theory [23-26]. Although results are preliminary (because a second experiment is required to test attachment anxiety and avoidance), state elevations in psychopathy might facilitate increases in directional heightening of anxiety and avoidance responses, yet without compromising secure attachment. That is, it seems possible, that anxiety and avoidance have opposing directionality subsumed within each scale, invisibly collapsed by way of lost information about self and other. This may also have implications for avoidant, preoccupied, and fearful attachment styles. Results point out that human thinking is paradoxical, where survival threat can stabilise bonds, ensuring that empathy for one's close loved ones is retained, but whilst increasing survival-based self-centredness, concurrently stabilising anxiety, in a lowered need for approval. We summaries this preliminary find in the fortified-cognition hypothesis [51,52].

We suspect that the instincts to protect children and close loved ones are deeply implicated with human territoriality and with the survival instinct. That is, during survival threats through territorial incursions, child rearing and close bonding with loved ones are preserved. Core empathy and attachment processes are preserved, but only for those who are not alien, and who are not territorially threatening. Empathy and its associated affect from the warm spectrum, as well as attachment and bonding processes for loved ones is sustained. At the same time, directional psychopathy is elevated for select targets. Theory states that focussing upon deposing a common shared enemy, an 'invading deviant', when it is a collective focus, has potential to augment collective empathy and relationship processes. In regards to children of the morally alien culture, it is unclear from this study how attachment cognition for the offspring of aliens is impacted. We suspect that the survival instincts thinking about mutual exclusivity or young children would be less impacted by psychopathic cognition than it is for adults $[53,54]$.

Research also warns that people may respond on the two dimensions of attachment of self and other, contingently. There are factors of context from the person's sexuo-emotional and socio-cultural background that impact upon activation of attachment processes. When faced with a territorial incursion based on sexuo-emotional and socio-cultural vector conflicts, responses on attachment items changed for participants. It follows that how relationships form, evolve, devolve and end, is based substantially upon sexuo-emotional, and sociocultural conflict, harmony and context. In particular, the activities of the targeting scanner of the psychopathic modular mind, and its response to threats in a socio-cultural context, mean it has capacity to impact how one reads and interprets their close relationships. Survival threat then and attributions borne of the psychopathic modular mind influence, for example, one's self focus, whilst predisposing people to relegate relationships as secondary, especially for those who are not close loved ones.

Within revised theory, mixed socio-cultural compositions mean that predicting trends in collective psychopathy can be achievable by coding directional vectors, deliberately in future research. How individuals experience socio-cultural, socio-affective, socio-spiritual and socio-sexual conflicts vary. Individual differences in prominence of one or other vector of influence means that idiographic assessment and measurement practices can be defined that assist to isolate which vectors are more influential for individual thinkers. We term the capacity for relative weighting of vector conflicts vector-grounding theory, which is to be developed in subsequent research. Means of measuring the strength, weight or resistance of a territorial hold over an attachment concept has important implications for understanding change.

\section{Conclusions}

We anticipate that future attachment research that matches participants on socio-sexual and socio-spiritual vectors, in particular has potential for greatest psychopathy induction, wherever moral deviants are counter-opposed most obviously on these two domains. Further, any territorial vector locked to ideas about a deity are expected to be the most pernicious and resistant to change, if they are grounded in territorial, survival threat. That is because territoriality over child rearing practices is most obviously elicited when parenting adults face spiritually alien peoples, especially where an alien spirituality espouses serious differences in deity-sponsored and deity-condemned sexual practices. Future research should also consider how to interpret adaptive facility for attachment-related thinking and behaviour. Means of understanding which vectors most easily break a territorial hold over sexuo-affective conflicts are of especial significance in future research. Another important area of research should formulate variations in theory, within theories of hyper-activation and attachment.

\section{References}

1. Buss DM (2009) How can evolutionary psychology successfully explain personality and individual differences?. Perspect Psychol Sci 4: 359-366.

2. Buss DM (2011) Evolutionary psychology: The new science of the mind Boston, MA: Allyn \& Bacon.

3. Buss DM, Duntley JD (2008) Adaptations for exploitation. Group Dyn 12: 53-62.

4. Buss DM, Hawley P (2011) The evolution of personality and individual differences. New York, NY: Oxford University Press.

5. Confer JC, Easton JE, Fleischman DS, Goetz C, Lewis DM, et al. (2010) Evolutionary psychology: Controversies, questions, prospects, and limitations. Am Psychol 65: 110-126.

6. Pinker S (2002) The blank slate. New York, NY: Norton.

7. Tooby J, Cosmides L (2005) Conceptual foundations of evolutionary psychology. New York, NY: Wiley. 5-67.

8. Mihailides, Galligan, Bates (2017) Psychopathy Induction and Empathy.

9. Mihailides, Galligan, Bates (2017) Reconceptualising psychopathy. J Foren Psy 2.

10. Ainsworth MD, Blehar MC, Waters E, Walls S (1978) Patterns of attachment: A psychological study of the Strange Situation. Hillsdale, NJ: Erlbaum

11. Bowlby J (1975) Attachment and loss: Separation anxiety and anger. 2: 1-325

12. Bowlby J (1982) Attachment and loss: Attachment. 1: 1-326.

13. Bowlby J (1985) Attachment and loss: Loss sadness and depression. 3: 1-355

14. Hazan C, Shaver P (1987) Romantic love conceptualised as an attachment process. J Pers Soc Psychol 52: 511-524.

15. Bartholomew K, Horowitz LM (1991) Attachment styles among young adults: A test of a four category model. J Pers Soc Psychol 61: 226-224.

16. Main M, Hesse E (1990) Parents unresolved traumatic experiences are related to infant disorganized attachment status: is frightened and/or frightening parental behaviour the linking mechanism?', in Attachment in the Preschoo Years: Theory, Research and Intervention. University of Chicago Press, Chicago. 161-184.

17. Collins NL, Read SJ (1990) Adult attachment, working models and relationship quality in dating couples. J Pers Soc Psychol 58: 644-663. 
Citation: Mihailides S, Galligan R, Bates G (2017) Adaptive Psychopathy: The Quarantine Vector and Attachment. J Foren Psy 2: 126. doi: 10.4172/2475-319X.1000126

Page 9 of 9

18. Crowell JA, Treboux D (1995) A review of adult attachment measures: Implications for theory and research. Soc Dev 4: 294-327.

19. Griffin D, Bartholomew K (1994) The metaphysics of measurement: The case of adult attachment. London: Kingsley. 17-52.

20. Griffin D, Bartholomew K (1994) Models of the self and other: Fundamental dimensions underlying measures of adult attachment. J Pers Soc Psychol 67: 430-445.

21. Feeney JA, Noller $P$, Hanrahan $M$ (1994) Assessing adult attachment. In M. B. Sperling \& W. H. Berman (Eds.), Attachment in adults: Clinical and developmental perspectives. New York: Guilford.

22. Simpson J (1990) Influence of attachment styles on romantic relationships. J Pers Soc Psychol 59: 971-980.

23. Mikulincer M (1998). Adult attachment style and individual differences in functional versus dysfunctional experiences of anger. J Pers Soc Psychol 74: 513-524.

24. Mikulincer M (1998) Attachment working models and sense of trust: An exploration of interaction goals and affect regulation. J Pers Soc Psychol 74: 1209-1224.

25. Mikulincer M (1998) Adult attachment style and affect regulation: Strategic variations in subjective self-other similarity. J Pers Soc Psychol 75: 436-448.

26. Shaver PR, Mikulincer M (2007) Adult attachment strategies and the regulation of emotion. New York, NY, Guildford Press.

27. Li T, Chan DKS (2012) How anxious and avoidant attachment affect romantic relationship quality differently: A meta-analytic review. Eur J Soc Psychol 42: 406-419.

28. Bailey C, Shelton D (2014) Self-reports of faulty parental attachments in childhood and criminal psychopathy in an adult-incarcerated population: An integrative literature review. J Psychosoc Nurs Ment Health Serv 21: 365-374.

29. Taubner S, White L, Zimmerman J, Fonagy P, Nolte T (2013) Attachmentrelated mentalization moderates the relationship between psychopathic traits and proactive aggression in adolescence. J Abnorm Child Psychol 41: 929-938.

30. Baldwin MW, Keelan JPR, Fehr B, Enns V, Koh-Rangarajoo E (1996) Socialcognitive conceptualization of attachment working models: Availability and accessibility effects. J Pers Soc Psychol 71: 94-109.

31. Fraley RC, Waller NG, Brennan KA (2000) An item-response theory analysis of self-report measures of adult attachment. J Pers Soc Psychol 78: 350-365.

32. Lilienfeld SO, Andrews BP (1996) Development and preliminary validation of a self-report measure of psychopathic personality traits in noncriminal populations. J Pers Assess 66: 488-524.

33. Lilienfeld SO, Patrick CJ, Benning SD, Berg J, Sellbom M, et al. (2012) The role of fearless dominance in psychopathy: Confusions, clarifications, and fruitful new directions. Personal disord 3: 327-340.

34. Arnett PA, Howland EW, Smith SS, Newman JP (1993) Autonomic responsivity during passive avoidance in incarcerated psychopaths. Pers Individ Dif 14: 173-184.

35. Billias N (2010) Promoting and producing evil. 1-305.

36. Cloninger CR, Przybeck TR, Svrakic DM, Wetzel RD (1994) The temperament and character inventory (TCl): A guide to its development and use. St. Louis: Washington University Centre for Psychobiology of Personality.

37. Feeney J, Noller P (1990) Attachment style as a predictor of adult romantic relationships. J Pers Soc Psychol 58: 281-291.

38. Gray JA (1970) The psychophysiological basis of introversion-extroversion Behav Res Ther 8: 249-266.

39. Häkkänen-Nyholm H, Nyholm JO (2012) Psychopathy in economic crime, organised crime, and war crimes. West Sussex, UK: Wiley-Blackwell. 177-200.

40. Hare RD (1980) A research scale for the assessment of psychopathy in criminal populations. Pers Individ Dif 1: 111-117.

41. Hare RD (1991) The hare psychopathy checklist-revised. Toronto, ON, Canada: Multi-Health Systems.

42. Hare RD (2003) Manual for the hare psychopathy checklist-revised. Toronto, Canada: Multi Health Systems.

43. Hare RD, Neumann CS (2010) The role of antisociality in the psychopathy construct: Comment on Skeem and Cooke (2010). Psychol Assess 22: 446-454.

44. Leach MM, Harbin JJ (1997) Psychological ethics codes: A comparison of twenty-four countries. Int J Psychol 32: 181-192.

45. Levenson MR, Kiehl KA, Fitzpatrick CM (1995) Assessing psychopathic attributes in a noninstitutionalized population. J Pers Soc Psychol 68: 151-158.

46. Lynam DR, Miller JD (2012) Fearless dominance and psychopathy: A response to Lilienfeld et al. Personal Disord 3: 341-353.

47. Miller JD, Lynam DR (2012) An examination of the psychopathic personality inventory's nomological network: A meta-analytic review. Pers Disord 3: 305326.

48. Neumann CS, Robert D, Newman P (2007) The super-ordinate nature of the psychopathy checklist-revised. J Pers Disord 21: 102-117.

49. Neumann CS, Malterer MB, Newman JP (2008) Factor structure of the Psychopathic Personality Inventory (PPI): Findings from a large incarcerated sample. Psychol Assess 20: $169-174$.

50. Patrick CJ, Fowles DC, Krueger RF (2009) Triarchic conceptualization of psychopathy: Developmental origins of disinhibition, boldness, and meanness. Dev Psychopathol 21: 913-938.

51. Shariat SV, Assadi SM, Noroozian M, Pakravannejad M, Yahyazadeh O, et al (2010) Psychopathy in iran: A cross-cultural study. J Pers Disord 24: 676-691.

52. Skeem JL, Polaschek DLL, Patrick CJ, Lilienfeld SO (2011) Psychopathic personality: Bridging the gap between scientific evidence and public policy. Psychol Sci Public Interest 12: 95-162.

53. Snowden RJ, Gray NS (2010) Temperament and character as a function of psychopathy: relationships between the Psychopathy Checklist - Revised and the Temperament and Character Inventory in a sample of personality disordered serious or repeat offenders. J Forens Psychiatry Psychol 21: 815-833.

54. Fowles DC (1980) The three arousal model: Implications of gray's twofactor learning theory for heart rate, electrodermal activity, and psychopathy. Psychophysiology 17: 87-104. 